\title{
Occupational stressors in practicing psychological psychotherapists
}

\author{
Katja Petrowski ${ }^{1^{*}}$, Aike Hessel $^{2}$, Christiane Eichenberg $^{3}$, Elmar Brähler ${ }^{2}$ \\ ${ }^{1}$ Department of Psychotherapy and Psychosomatic Medicine, Dresden University of Technology, Dresden, Germany; \\ *Corresponding Author: katja.petrowski@tu-dresden.de \\ ${ }^{2}$ Department of Medical Psychology and Medical Sociology, Leipzig University Medical School, Leipzig, Germany; \\ aike.hessel@drv-oldenburg-bremen.de, elmar.braehler@medizin.uni-leipzig.de \\ ${ }^{3}$ Institute of Clinical Psychology and Psychological Diagnostics, University of Cologne, Köln, Germany; eichenberg@uni-koeln.de
}

Received 23 November 2013; revised 26 December 2013; accepted 4 January 2014

Copyright (C) 2014 Katja Petrowski et al. This is an open access article distributed under the Creative Commons Attribution License, which permits unrestricted use, distribution, and reproduction in any medium, provided the original work is properly cited. In accordance of the Creative Commons Attribution License all Copyrights (C) 2014 are reserved for SCIRP and the owner of the intellectual property Katja Petrowski et al. All Copyright (C 2014 are guarded by law and by SCIRP as a guardian.

\section{ABSTRACT}

Background: To the present, there has been no empirical clarification regarding to which extent psychological, physical, existential, and other stressors present health risks to psychotherapists. Methods: To identify the work strains of psychotherapists, German practitioners were interviewed using the model of the job security crisis. The constructs of this model as well as the occupational stressors and the individual state of health were measured by questionnaires. Results: In particular, the results brought light burdensome demands on time and high administrative demands as well as disappointing financial compensation. More than $25 \%$ of the participants felt that they were "financially burdened and/or very strongly burdened". Concerning the proportion of needs ("spending") and compensation ("reward"), this did not differ from the full-time employed German population of the same age group. However, concerning the "Expenditure-Reward-Imbalance", personal health was subjectively estimated as being worse: more physical complaints were reported and the health-related quality of life was lower. However, there were no differences in the number and intensity of physical complaints between psychotherapists and the general population. Conclusion: In sum, the demands of administrative processes, the stress due to the considerable temporal demands, and considerable dissatisfaction with the financial situation stand out for psychotherapists, in particular. These stresses and strains notwithstanding, psychotherapists do not have a disadvantageous ratio of stressors to gratifications. The study illustrates the high degree of discontent practicing psychotherapists feeling about their financial situation. This fact is important in regard to professional policy and has a direct effect on the therapeutic process.

\section{KEYWORDS}

Compensation; Health; Job Satisfaction; Job Satisfaction Crisis; Psychotherapists; Stress

\section{INTRODUCTION}

Psychotherapists in private practice are heavily burdened psychologically, physically as well as existentially. The stressors that psychotherapists have to contend with in private practice were identified as the daily confrontation with stressful emotions due to the therapeutic process [1], role ambiguity [2], having to deal with mental disorders on a daily basis [3,4] as well as social isolation and a lack of social stimulation due to working entirely unassisted [5]. One particular physical stressor is the predominantly sedentary occupation during psychological work, for which there is no physical outlet. Beyond that, economic uncertainty functions as an existential stressor [6].

Altogether, these stressors may present a health risk to psychotherapists as described in the model of job satisfaction crisis $[7,8]$. Occupational performance based on social reciprocity needs to be compensated by specified rewards (gratuities) such as appreciation, an income pro- 
portionate to performance, job security, and promotion. This model postulates that an imbalance between the performance and the reward received (extrinsic model component) leads to health risks $[9,10]$ as a chronic imbalance between high expenditures and low financial reward (extrinsic model components) elicits negative emotions and activates the central nervous system, thus causing stress (the job satisfaction crisis), which in turn leads to increased health risks. The frequency and the intensity of continuously experienced stress do not only alter the external circumstances but also the personality characteristics (individual occupational expenditure aptness). An exaggerated occupational expenditure aptness (intrinsic model component) results in a higher risk of illness [9, $10]$.

The high stressor load and the imbalance lead to a limited state of health in psychotherapists as postulated by this model. Various investigations revealed subjective health limitations for psychotherapists (e.g. [11-13]). Psychotherapists frequently felt overwhelmed by their work, strained, worn out, uncreative, and exhausted as well as frustrated and very tired [2]. Compared to the standard age sample, psychotherapists exhibited a lower subjective state of health in regard to "vitality", "social functionality", and "emotional role functioning" [4]. In addition, psychotherapists suffered more “exhaustion” [2,14, 15].

Based on the literature it can be proposed that psychotherapists suffer from a high accumulation of occupational stressors. Psychotherapists may have a higher level of stress due to the poorly compensated high occupational demand as well as the financial concerns (Hypothesis1). The model of job satisfaction crisis postulates that an accumulation of stressors leads to an imbalance in social reciprocity. Therefore, it can be assumed that psychotherapists may show an imbalance in reciprocity at high expenditure aptness and low experienced reward
(Hypothesis 2). Based on the model, an imbalance in social reciprocity affects the health of the psychotherapists. As shown in the literature, a psychotherapist may report a limited subjective state of health based on an imbalanced work load (Hypothesis 3).

\section{METHODS}

\subsection{Sample and Design}

In 2004, certified practicing psychological psychotherapists ( $N=1385$, 905 women, 480 men) representing all German health insurance companies, were invited to participate in a written survey in order to investigate the situation of practicing psychological psychotherapists in Germany. A total of 488 psychotherapists participated in the survey, resulting in a return ratio of $35.2 \%$. The return ratio may be labelled as satisfactory since similar survey studies exhibited comparable (or even lower still) ratios (see e.g. [16,17]).

Table 1 represents the socio-demographic parameters of the sample. With an average age of 47.4 years, the psychologists showed an almost similar age as the German physicians, whose average age was 50.4 years [18]. Among the participating psychotherapists, $71.9 \%$ were female. This stems from the fact that within the occupational group of psychotherapists women dominate in terms of numbers (65.5\% of the censused psychological psychotherapists from the selected Federal States were women vs. $38.2 \%$ of women among the employed physicians in Germany).

The majority of the participating psychological psychotherapists indicated behavioral therapy as their main therapeutic method (54.6\%). Depth psychology-based psychotherapy followed in second place $(32.3 \%$ of the participating psychotherapists), and psychoanalysis was in third place with $13.1 \%$ of the participating psychotherapists.

Table 1. Sample characteristics.

\begin{tabular}{|c|c|c|c|c|}
\hline & & Total $(n=488)$ & Male $(n=137)$ & Female $(n=343)$ \\
\hline Age & $\begin{array}{c}M \\
S D \\
\text { Range }\end{array}$ & $\begin{array}{c}47.4 \\
7.5 \\
29-84\end{array}$ & $\begin{array}{c}48.6 \\
8.6 \\
32-84\end{array}$ & $\begin{array}{c}46.9 \\
6.9 \\
29-65\end{array}$ \\
\hline East/West & $\begin{array}{l}\text { East } \\
\text { West }\end{array}$ & $\begin{array}{l}251(53.1 \%) \\
222(46.9 \%)\end{array}$ & $\begin{array}{l}71(52.6 \%) \\
64(47.4 \%)\end{array}$ & $\begin{array}{l}180(53.2 \%) \\
158(46.8 \%)\end{array}$ \\
\hline Marital status & $\begin{array}{c}\text { Single } \\
\text { Married } \\
\text { Married, living apart } \\
\text { Widowed/Divorced }\end{array}$ & $\begin{array}{c}82(17.1 \%) \\
307(64.1 \%) \\
17(3.6 \%) \\
73(15.2 \%)\end{array}$ & $\begin{array}{c}31(22.6 \%) \\
91(66.4 \%) \\
5(3.6 \%) \\
10(7.3 \%)\end{array}$ & $\begin{array}{c}51(14.9 \%) \\
216(63.2 \%) \\
12(3.5 \%) \\
63(18.4 \%)\end{array}$ \\
\hline In a relationship & $\begin{array}{l}\text { Yes } \\
\text { No }\end{array}$ & $\begin{array}{c}400(84.0 \%) \\
76(16.0 \%)\end{array}$ & $\begin{array}{c}122(90.4 \%) \\
13(9.6 \%)\end{array}$ & $\begin{array}{c}278(81.5 \%) \\
63(18.5 \%)\end{array}$ \\
\hline Children & $\begin{array}{l}\text { Yes } \\
\text { No }\end{array}$ & $\begin{array}{c}387(80.8 \%) \\
92(19.2 \%)\end{array}$ & $\begin{array}{c}109(79.6 \%) \\
28(20.4 \%)\end{array}$ & $\begin{array}{c}278(81.3 \%) \\
64(18.7 \%)\end{array}$ \\
\hline Main therapeutic method & $\begin{array}{c}\text { Psychoanalysis } \\
\text { Depth Psychology } \\
\text { Behavioral Therapy }\end{array}$ & $\begin{array}{c}61(13.1 \%) \\
150(32.3 \%) \\
254(54.6 \%)\end{array}$ & $\begin{array}{l}23(17.3 \%) \\
27(20.3 \%) \\
83(62.4 \%)\end{array}$ & $\begin{array}{c}38(11.4 \%) \\
123(37.0 \%) \\
171(51.5 \%)\end{array}$ \\
\hline
\end{tabular}




\subsection{Design}

The questionnaires were mailed out to certified practicing psychological psychotherapists asking about their socio-demographic data, education, and advanced training, occupational activities, the diagnostics and the therapy of mental disorders they were treating, occupational self-effectiveness expectations, income situation, state of health, life satisfaction, and social support. In addition, the following four instruments were included: the Subjective Complaints List [19], the Life Satisfaction Questionnaire [20], the Occupational Stress Questionnaire [21], and the Measurement of Effort-Reward Imbalance at Work [22].

\subsection{Instruments}

The components of the model of job satisfaction crisis were evaluated by the "Measurement of Effort-Reward Imbalance at Work" [22] which measures the extrinsic component "Expenditure" as well as "Reward" with the three subscales "Income and Occupational Promotion", "Appreciation", and "Job Security". The intrinsic model component includes the sum scale with "Occupational Expenditure Aptness". The item responses follow a fivepoint Likert scale for the extrinsic components and a four-point-Likert scale for the intrinsic components. High values for the extrinsic scales indicate high in both "expenditure" and/or "reward". On the basis of the acceptance that an unfavourable connection of "expenditure" and "reward" leads to health risks, the values of both scales were set in relation to one another by forming a quotient ("expenditure-reward-imbalance"). High values on the intrinsic scales referred to high expenditure aptness. The psychometric characteristics of the instrument were examined in several studies and proved satisfactory [22,23].

The “Occupational Stress Questionnaire” [21] measures various stressful moments specific to an activity in several medical occupations. This questionnaire consists of ten items rated on a five-point Likert scale. Furthermore, a sum value can be formed for the quantification of the stressors.

In order to examine the connection between the appropriate variables of the workload and the health-oriented parameters, the following health measures were used:

The subjective estimate of one's own health state was determined by means of the item "how would you describe your current state of health?-poor, less than well, satisfied, well, very well". This approach was selected as this individual item predicted morbidity and mortality better than "objective" measurements and estimates of the state of health (e.g. [24-29]).

The total scale of the Giessener Subjective Complaints
List (GGB-24) was computed for the compilation of the following four physical complaints and their intensity: fatigue, gastrointestinal, heart-related, and orthopaedic complaints [19]. In addition, the total scores indicated the pressure caused by these complaints. Based on several representative studies, the internal consistency was satisfactory, and the construct validity was good $[30,31]$.

Health-oriented Life Satisfaction was verified by means of the Life Satisfaction Questionnaire (FLZ) [20]. This well-established questionnaire assesses life satisfaction in ten areas of life: health, income/financial situation, occupation/work, housing/living conditions, family life/children, partner relationship/sexuality, friends/acquaintances, leisure time/hobbies. Each of the ten scales consists of seven items rated on a seven-point Likert scale. The internal consistency was high, and the validity of the factorial structure as well as the association of the scales to personality characteristics could be proved [32].

\subsection{Statistical Analyses}

Frequency and average value data were reported. In order to examine the influence of different socio-demographic characteristics on the examined parameters as well as to safeguard against possible statistical differences in comparing psychotherapists to the general population and/or in comparing psychotherapists to (Saxon) primary care physicians, more-factorial analyses of variance were used in each case. The connections between the parameters of workload and the subjective health measures (already proved in other samples) were confirmed as correlations were determined.

In order to have a reference frame for the effect of the stressors, the state of health as well as the effort and reward balance of psychotherapists, the data were compared to those from the general family practitioners in private practice as well as to those from a representative sample of the general population.

The data from the general population used in the computations came from a population-representative survey conducted in 2002, to which an overall number of 2089 people responded. Since the examined topic was only relevant for employed individuals and given that there were age effects to be expected as well, a partial sample was pulled from this population-representative sample. The partial sample corresponded to the sample of psychotherapists in the age distribution active in the context of full-time occupation. In all, $N=501$ individuals aged 35 - 66 belonged to this partial sample (174 women, 327 men, 288 West Germans, 213 East Germans).

The data of the (Saxon) primary care physicians came from a survey conducted in 2003 with $N=451$ primary care physicians practicing in Saxony, 32 - 76 years of age ( $M=51.9$ years, 177 men, 264 women, see [33]). 


\section{RESULTS}

Occupational stress. In the first hypothesis concerning occupational stress in psychotherapists it was postulated, that psychotherapists suffer from a high accumulation of occupational stressors.

Table 2 shows the frequencies and average values of the "Occupational Stress Questionnaire". The psychotherapists felt the most severely stressed by the high administrative costs and the extensiveness of insurance records (45.7\% "strongly" or "very strongly" burdened) as well as the large temporal demand (46.2\% have "too little time for personal life", "strongly and/or very strongly burdened", and $45.6 \%$ have "too little spare time"). Furthermore, $28 \%$ of the participating psychotherapists were very stressed due to financial concerns. Above that, the most stressful factors were the high level of responsibility (89.5\% "moderately" stressed and 26.7\% "very" stressed), the time pressure (64.4\% "moderately" stressed and $32.1 \%$ "very" stressed), and the increase in the workload (56.7\% "moderately" stressed and $26.7 \%$ "very" stressed). In contrast, frequent layoffs and overtime work did not influence the stress load (see Table 2).
Concerning the influence of the socio-demographic data (see Table 2), the male participants deemed "high work pace/time pressure" to be more stressful than the female participants did $(p<0.001)$. Interestingly, the psychoanalysts experienced more "financial concerns" than the depth psychologists and the behavioral therapists $(p=0.01)$.

In comparison to the primary care physicians (Table 2), the psychotherapists felt significantly less stressed due to elevated straining qualities (total scale). In particular, this included "fast work pace/time pressure" $(p<$ $0.001)$, "too little time for personal life" $(p<0.001)$, "unpredictable workload" $(p<0.001)$, "lacking compatibility with family life" ( $p<0.001)$, "too little spare time" ( $p<0.001)$, and "the high administration costs /cash accounts" $(p<0.001)$ (2-Way analysis of variance with factors "sample" and "gender").

Effort- and reward-balance. The second hypothesis concerning the effort and reward balance proposed that the imbalance of social reciprocity leads to stress. The frequency and average values for the items of the "Measurement of Effort-Reward Imbalance at Work" is shown in Table 3.

Table 2. Scale characteristics of the "Occupational Stress Questionnaire” and comparison to the sample of (Saxon) primary care physicians.

\begin{tabular}{|c|c|c|c|c|c|c|c|c|}
\hline Item & $\begin{array}{l}\text { Item Value } 1 \\
\text { (I am not } \\
\text { stressed) }\end{array}$ & 2 & 3 & 4 & $\begin{array}{c}5 \\
\text { (I am very } \\
\text { stressed) }\end{array}$ & $M(S D)$ & $\begin{array}{l}\text { Socio-Demographic } \\
\text { Influence }^{(1)}\end{array}$ & $\begin{array}{c}\text { Psychotherapist } \\
\text { (PT) vs. (Saxon) } \\
\text { Primary Health } \\
\text { Care Physician (PHCP) }^{(2)}\end{array}$ \\
\hline $\begin{array}{c}\text { Fast work pace/time } \\
\text { pressure }\end{array}$ & $12.8 \%$ & $28.4 \%$ & $23.7 \%$ & $26.5 \%$ & $8.6 \%$ & $2.9(1.18)$ & $\begin{array}{l}\text { Men }>\text { Women }^{* *} \\
\text { (M-M: } 3.13 \\
\text { M-W: } 2.82)\end{array}$ & $\begin{array}{l}\text { PT }<\text { PHCP } \\
\text { (M-PHCP: 3.32) }\end{array}$ \\
\hline $\begin{array}{l}\text { High responsibility } \\
\text { for others }\end{array}$ & $12.6 \%$ & $34 \%$ & $28.9 \%$ & $21 \%$ & $3.5 \%$ & $2.69(1.05)$ & $\begin{array}{l}\text { West }<\text { East }^{* * *} \\
(\text { M-W: } 2.56 \\
\text { M-E: } 2.76)\end{array}$ & \\
\hline Unpredictable workload & $9.3 \%$ & $36.1 \%$ & $24.7 \%$ & $23.9 \%$ & $6.0 \%$ & $2.81(1.09)$ & & $\begin{array}{c}\text { PT }<\text { PHCP } \\
\text { (M-PHCP: 3.12) }\end{array}$ \\
\hline $\begin{array}{l}\text { Too little time } \\
\text { for private life }\end{array}$ & $9.4 \%$ & $23 \%$ & $21.4 \%$ & $33.5 \%$ & $12.7 \%$ & $3.17(1.19)$ & & $\begin{array}{l}\text { PT }<\text { PHCP } \\
\text { (M-PHCP: 3.59) }\end{array}$ \\
\hline $\begin{array}{l}\text { Lacking compatibility } \\
\text { with family life }\end{array}$ & $19.9 \%$ & $29.8 \%$ & $25.3 \%$ & $19 \%$ & $6 \%$ & $2.61(1.17)$ & & $\begin{array}{c}\text { PT }<\text { PHCP }^{* * *} \\
\text { (M-PHCP: 3.24) }\end{array}$ \\
\hline Too little freetime & $11.1 \%$ & $21.4 \%$ & $22 \%$ & $33.1 \%$ & $12.5 \%$ & $3.15(1.21)$ & & $\begin{array}{c}\text { PT }<\text { PHCP } \text { PH** }^{* * *} \\
(\text { M-PHCP: 3.48) }\end{array}$ \\
\hline Financial concerns & $22.6 \%$ & $26.5 \%$ & $22.8 \%$ & $20 \%$ & $8 \%$ & $2.64(1.25)$ & $\begin{array}{c}\mathrm{PA}>\mathrm{DP}>\mathrm{BT}^{*} \\
(\mathrm{M}: 2.9 / 2.79 / 2.49)\end{array}$ & \\
\hline $\begin{array}{l}\text { High levels of } \\
\text { competition } \\
\text { with colleagues }\end{array}$ & $62.4 \%$ & $25.7 \%$ & $8.4 \%$ & $2.9 \%$ & $0.6 \%$ & $1.54(0.82)$ & & \\
\hline $\begin{array}{l}\text { High administrative } \\
\text { expenses/extensive } \\
\text { insurance records }\end{array}$ & $8.6 \%$ & $15.2 \%$ & $20.5 \%$ & $34.3 \%$ & $21.4 \%$ & $3.45(1.22)$ & & $\begin{array}{c}\text { PT }<\text { PHCP }^{* * *} \\
(\mathrm{M}-\mathrm{PHCP}: 4.20)\end{array}$ \\
\hline $\begin{array}{c}\text { Unsure of } \\
\text { occupational future }\end{array}$ & $16 \%$ & $27.2 \%$ & $28.4 \%$ & $22 \%$ & $6.4 \%$ & $2.76(1.15)$ & & \\
\hline Total value & & & & & & $27.58(6.44)$ & & $\begin{array}{c}\text { PT }<\text { PHCP } \\
\text { (M-PHCP: 30.31) }\end{array}$ \\
\hline
\end{tabular}

Note. ${ }^{(1)} 3$-Way-analysis of variance with factors “Gender”, "Location of Practice”, "Main Therapeutic Method”. ${ }^{(2)} 2$-Way-analysis of variance with the factors "Sample" and "Gender". ${ }^{*} p<0.05,{ }^{* *} p<0.01,{ }^{* * *} p<0.001$. Mean (M) and standard deviation (SD). 


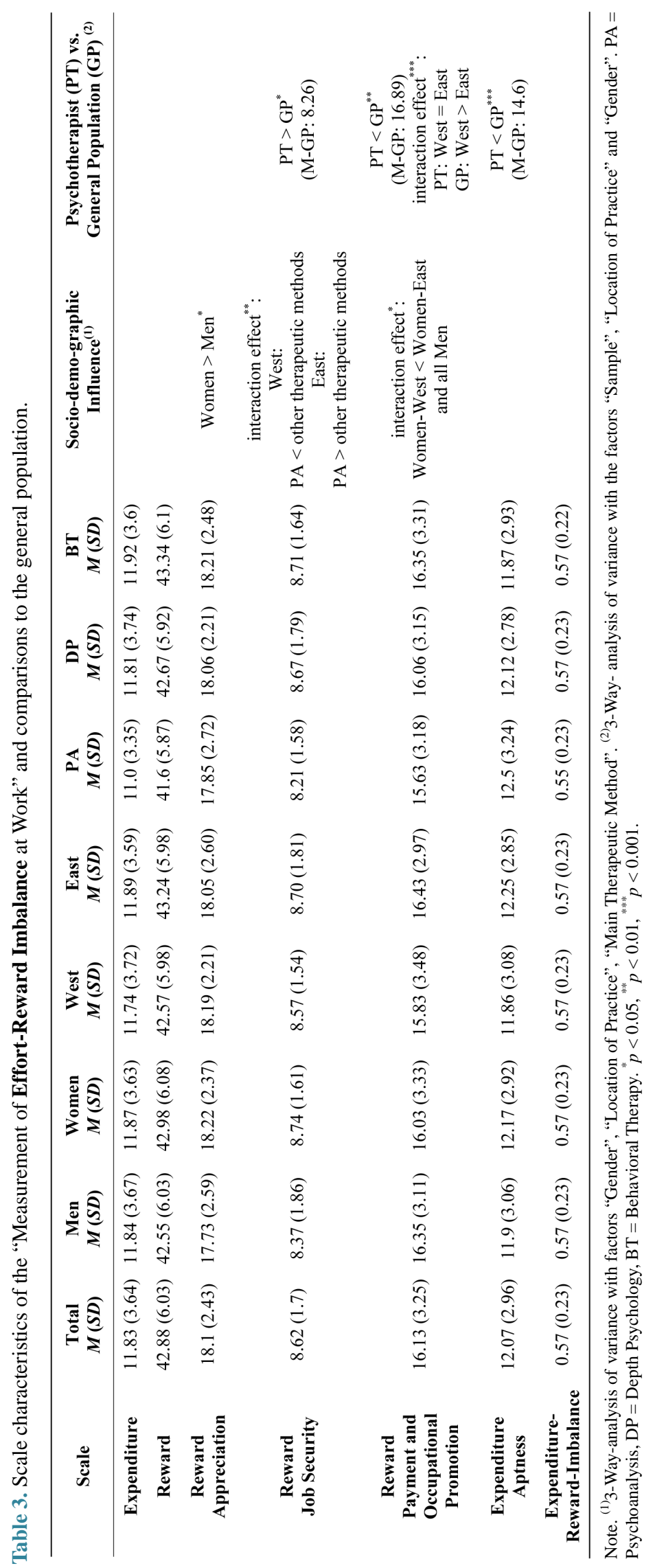


In respect to "Reward-Income and Occupational Promotion”, psychotherapists were predominately very satisfied with their "Occupational Promotion". However, they felt very dissatisfied with their "Income" (70.5\% were "moderately" stressed and $27.8 \%$ were "very" stressed that their salary did not correspond to the performed services). Nevertheless, the therapists reported high levels of deeply-felt appreciation and cooperative support ("Reward-Appreciation"). In respect to the "Reward-Job Security", relatively few of the participants felt stressed by the idea that their job might be endangered (6.2\% "moderately stressed and 3.1\% "very" stressed). A substantial percentage of the participants however anticipated a deterioration of their occupational situation (47.2\% “moderately" stressed and 19.3\% "very stressed"). Furthermore, the participating psychotherapists were generally only slightly apt to expand occupationally ("Occupational Expenditure Aptness"). Table 3 shows the values of the specific scales.

The three-factorial analysis of variance with the factors "gender", "location of the practice" (East vs. West Germany), and "main therapeutic method" (psychoanalysis vs. depth psychology-based psychotherapy vs. behavioral therapy) resulted in significant differences (see Table 3). The participating women reported more perceived "Reward" in "Appreciation" than the participating men $(p<0.05)$. The psychoanalysts whose practices were in West Germany expressed less perceived "Reward" in "Job Security" than the depth psychologists and behavioral therapists whose practices were also in the West. In contrast, in East Germany the correlation concerning this matter was reversed (interaction effect $p<$ 0.01). The psychoanalysts with practices in East Germany expressed more perceived "Reward" in "Job Security" than the participating depth psychologists and behavioral therapists with practices in the East. The female psychotherapists in West Germany experienced less "Reward" in the form of "Income and Occupational Promotion" than all of the other surveyed participants (interaction effect $p<0.05$ ).

In order to show the specificity of the results obtained from the psychotherapists, the psychotherapists were compared to the general population. The three-factorial analysis of variance with the factors "survey group" (age-appropriate, full-time employed general population vs. psychotherapists), "gender", and "residential and/or practice location" (East vs. West Germany) resulted in the following significant differences: The subscale "RewardJob Security" was more manifest for the psychotherapists than the age-appropriate, full-time employed general population. This means that psychotherapists felt comparatively more rewarded when it came to "Job Security". The subscale "Reward-Income and Occupational Promotion", however, was less pronounced for the psycho- therapists than the age-appropriate, full-time employed general population $(p<0.01)$, meaning that psychotherapists felt less well compensated than the general population. The scale "Expenditure Aptness" was significantly less pronounced for the psychotherapists than the ageappropriate, full-time employed general population, meaning that psychotherapists were comparatively less apt to expand. The psychotherapists did not differ significantly from the age-appropriate, full-time employed general population concerning the characteristics of the scale "Expenditure", the total scale "Reward", and the subscale "Reward-Appreciation". The factor "Expenditure —Reward-Imbalance" also did not show any significant differences.

State of health. The third hypothesis concerning the state of health of psychotherapists proposed that the psychotherapist might report limited subjective health. In order to examine the relationship of the work load to subjective health, the subjective estimate of one's own health, the number and intensity of physical complaints, and health-oriented life satisfaction were correlated (see Table 4).

The work-load parameters correlated significantly moderate with the health of the psychotherapists. This meant that when reinforcing the "Expenditure-Reward-Imbalance", one's own health was estimated as subjectively worse: more physical complaints were reported (GBB-24) and the health-related quality of life was lower (FLZ). The same applied to the increased sum in the items relating to the stressful qualities on the "Questionnaire of Occupational Stress".

In order to show the specificity of the results obtained from the psychotherapists, the psychotherapists were compared to the general population. The three-factorial analysis of variance with the factors "survey group" (age-appropriate, full-time employed general population vs. psychotherapists), "gender", and "residential and/or practice location" (East vs. West Germany) resulted in the following significant differences: the psychotherapists showed significantly more fatigue symptoms as well as more heart-related complaints than the general population. However, there were no differences in the number and intensity of physical complaints. Concerning life satisfaction, the psychotherapists were more dissatisfied concerning their financial situation and their leisure time compared to the general population (see Table 4).

\section{DISCUSSION}

The literature indicated that the occupation of a psychotherapist in private practice was accompanied by a high accumulation of occupational stressors. The range of the stressors containing a health risk in regard to a career in psychotherapy can be described by the model of 
Table 4. Correlations and parameters of occupational stress and subjective measures of health.

\begin{tabular}{|c|c|c|c|c|c|}
\hline Scale & $\begin{array}{c}\text { Measurement of } \\
\text { Effort-Reward Imbalance at work: } \\
\text { Expenditure-Reward-Quotient }\end{array}$ & $\begin{array}{l}\text { Occupational Stress } \\
\text { Questionnaire: } \\
\text { Total Value }\end{array}$ & $\begin{array}{c}\text { Psychotherapist } \\
M(S D)\end{array}$ & $\begin{array}{l}\text { General } \\
\text { population } \\
M(S D)\end{array}$ & $p(F)$ \\
\hline Subjective estimate of own Health & -0.304 & -0.398 & & & \\
\hline $\begin{array}{l}\text { Number and intensity of Body } \\
\text { Complaints (GBB-24) }\end{array}$ & 0.358 & 0.355 & $37.31(9.900)$ & $37.61(12.420)$ & 0.618 \\
\hline Fatigue (GBB-24) & 0.360 & 0.324 & $0.85(4.350)$ & $10.09(4.274)$ & 0.000 \\
\hline Gastrointestinal complaints (GBB-24) & 0.212 & 0.239 & $7.74(2.464)$ & $8.02(2.895)$ & 0.049 \\
\hline Heart related complaints (GBB-24) & 0.186 & 0.198 & $7.47(2.168)$ & $8.06(3.101)$ & 0.000 \\
\hline Orthopaedic complaints (GBB-24) & 0.306 & 0.314 & 11.31 (3.769) & $11.45(4.428)$ & 0.532 \\
\hline Health Related Quality of Life (FLZ) & -0.320 & -0.404 & $37.85(6.674)$ & $38.12(7.029)$ & 0.431 \\
\hline Financial Related Quality of Life (FLZ) & -0.395 & -0.522 & $30.76(8.256)$ & $33.48(8.651)$ & 0.000 \\
\hline $\begin{array}{l}\text { Leisure time Related Quality of Life } \\
\text { (FLZ) }\end{array}$ & -0.493 & -0.645 & $30.97(8.164)$ & $33.85(8.382)$ & 0.000 \\
\hline Personal Related Quality of Life (FLZ) & -0.208 & -0.251 & $38.79(4.887)$ & $38.40(5.632)$ & 0.117 \\
\hline
\end{tabular}

Note. All correlation coefficients significant with $p=0.000$.

job satisfaction crisis $[7,8]$. The poorly compensated high demand of the job in combination with the financial concerns may be particularly imbalanced in psychotherapists. According to the model, an imbalanced social reciprocity affects health. Therefore, the subjective state of health, the range of stressors, and social reciprocity were investigated in this study.

Based on the present data, the different qualities of stress relating to the work of a psychotherapist could be determined and correlated with the subjective state of health. The stressors included administrative procedures, a strong temporal demand, high responsibility, and the high degree of dissatisfaction the psychotherapists felt with their financial situation. Only a small percentage of participants agreed that the income/salary was appropriate for the services rendered, but most of the surveyed participants felt moderately stressed in reference to " $f i$ nancial concerns". Various other studies also alluded to the high degree of dissatisfaction felt by the psychotherapists in regard to their financial situation [34,35]. Accordingly, more than one-third of those surveyed indicated that they were unable to maintain themselves and their families on their income, and half of them believed that their income was less than that of others who had comparable training. The life satisfaction of practicing German psychological psychotherapists concerning their financial situation was significantly lower than that of both the age-appropriate general population of a comparable education level [20] and the (Saxon) primary care physicians [33]. In addition, practicing psychological psychotherapists were found to be just as dissatisfied with their income situation as the age-appropriate general population of a comparable education level [7,36]. More than half of these colleagues had a maximum income of 30,000 Euros per year (after taxes) and viewed their income as insufficient to properly provide for their families.
A small percentage of the psychotherapists with this kind of an income were even the main or the sole income of a household with children to support. At the same time, the average income of the general German population was 40,642 Euros per year (after taxes). In addressing the situation, Bowe (1999, p. 255) speaks of the "economic emergency that psychotherapists and their families face".

The model of job satisfaction crisis $[7,8]$ postulates that the stressors of a career in psychotherapy contain a health risk. Imbalanced social reciprocity especially affects the state of health. When comparing practicing psychological psychologists to the age-appropriate, full-time employed general population, no significant differences can be determined on the dimensions "Expenditure", "Reward", and the "Expenditure-reward-quotient". Concerning the "Exaggerated Expenditure aptness" (intrinsic model component), psychotherapists exhibit significantly lower values than the general population. This is contrasted elsewhere with descriptive characteristics of affiliated auxiliary occupations that let them assume a higher "Expenditure Aptness" i.e., inclination to altruistic behaviors [37], high ideals [38], and dependent relationships that blur boundaries, and considering one's own early childhood deprivations [1]. Perhaps, self-awareness and opportunities for supervision are important healthbenefitting aspects for the comparatively low results of "Expenditure Aptness". An additional explanation might be that the psychotherapists usually know about the harmful effects of exaggerated expenditure aptness, both to themselves and to the therapeutic process.

Regarding the "Expenditure-Reward-Imbalance", the psychotherapists' health state was estimated as low with several physical complaints and a lower health-related quality of life. The worst subjective state of health was also connected to the summary increase in the stressful qualities of the occupational stressors. 
Apart from the possibility of answering tendencies, the so far discussed findings and interpretations are subject to further methodical limitations. It might illustrate too small of an "Expenditure" within the very special sample of those surveyed using the "Measurement of Occupational Expenditure Questionnaire" since the items of the scale "Expenditure" surely do not include the specific stresses of working as a practicing psychotherapist [1,3, 4]. The additionally used "Occupational Stress Questionnaire" identifies the discontent regarding the administrative processes and the strong temporal demand as prominent stressors, yet does not illustrate the very specific psychological demand of therapeutic work sufficiently. Considering the moderate response rate, the problem of selection errors during sample recruitment (volunteer bias, in particular) must also be brought up for discussion. Additionally, interpretive restrictions arise due to the fact that this study is a cross-section study. Neither correlation analysis (surveyed parameters being occupational stress and subjective measure of health) is exhaustively possible when it comes to causation. In order to analyse the causal influences of the different components of the model, linear structural equation models need to be calculated. At the same time, conclusions cannot be drawn regarding the dependability of the reported stresses and the alleged dispositional character of the sample's "expenditure aptness" in the sense of one's intrapersonal to relatively time-stable personality characteristics.

\section{CONCLUSION}

The work of a practicing psychotherapist is accompanied by various stressors. The demands of administrative processes, the stress due to the considerable temporal demands, and considerable dissatisfaction with the financial situation stand out, in particular. These stresses and strains notwithstanding, psychotherapists do not have a disadvantageous ratio of stressors to gratifications.

\section{COMPETING INTERESTS}

The authors declare that they have no competing interests.

\section{AUTHORS' CONTRIBUTIONS}

EB and CA were responsible for the conception and the design of the study as well as the acquisition of the data. MR performed the statistical analysis and substantially contributed to the interpretation of the data. KP contributed to the interpretation of the data, wrote the first and final version of the manuscript, and critically revised the manuscript for intellectual content. All the authors read and approved the final version of the manuscript for publication.

\section{REFERENCES}

[1] Geyer, M. (2008) Heimat und Identität des Psychothera- peuten. In: Geyer, M. and Plöttner, G., Eds., Psychodynamische Psychotherapie und ihre Therapeuten Psychosozial-Verlag, Gießen, 97-112.

[2] Lee, J., Lim, N., Yang, E. and Lee, S.M. (2011) Antecedents and consequences of three dimensions of burnout in psychotherapists: A meta analysis. Professional Psychology: Research and Practice, 42, 252-258. http://dx.doi.org/10.1037/a0023319

[3] Reimer, C. (2000) Occupational stressors and problems of the quality of life in psychotherapists. Persönlichkeitsstörungen: Theorie und Therapie, 4, 69-75.

[4] Reimer, C., Jurkat, H.B., Vetter, A. and Raskin, K. (2005) Quality of life in licensed psychotherapists. A comparative study of medical and psychological psychotherapists. Psychotherapeut, 50, 107-114. http://dx.doi.org/10.1007/s00278-005-0411-8

[5] Cushway, D. and Tyler, P. (1996) Stress in clinical psychologists. International Journal of Social Psychiatry, 42, 141-149. http://dx.doi.org/10.1177/002076409604200208

[6] Hessel, A., Geyer, M., Brähler, E. and Eichenberg, C. (2009) About the range-specific life satisfaction among established psychological psychotherapists. Zeitschrift für Psychotraumatologie, Psychotherapiewissenschaft und Psychologische Medizin, 3, 77-89.

[7] Siegrist, J. (1996) Social crises and health. Hogrefe, Göttingen.

[8] Siegrist, J. (2002) Effort-reward imbalance at work and health. In: Perrewe, P.L. and Ganster, D.C., Eds., Historical and current perspectives on stress and health, Elsevier, Amsterdam, 261-291.

http://dx.doi.org/10.1016/S1479-3555(02)02007-3

[9] Tsutsumi, A. and Kawakami, N. (2004) A review of empirical studies on the model of effort-reward imbalance at work: Reducing occupational stress by implementing a new theory. Social Science \& Medicine, 59, 2335-2359. http://dx.doi.org/10.1016/j.socscimed.2004.03.030

[10] Van Vegchel, N., de Jonge, J., Bosma, H. and Schaufeli, W. (2005) Reviewing the effort-reward imbalance model: Drawing up the balance of 45 empirical studies. Social Science \& Medicine, 60, 1117-1131. http://dx.doi.org/10.1016/j.socscimed.2004.06.043

[11] Eunha, K. (2007) Occupational Stress: A survey of psychotherapists in Korea and the United States. International Journal of Stress Management, 14, 111-120. http://dx.doi.org/10.1037/1072-5245.14.1.111

[12] Gilroy, P.J., Carroll, L. and Murra, J. (2002) A preliminary survey of counseling psychologists' personal experiences with depression and treatment. Professional Psychology: Research and Practice, 33, 402-407. http://dx.doi.org/10.1037/0735-7028.33.4.402

[13] Radeke, J.A.T. and Mahoney, M.J. (2000) Comparing the personal lives of psychotherapists and research psychologists. Professional Psychology: Research and Practice, 31, 82-84. http://dx.doi.org/10.1037/0735-7028.31.1.82

[14] Hessel, A., Geyer, M., Weidner, K. and Brähler, E. (2006) Subjective evaluation of their own health and healthrelated behavior among established psychological psychotherapists. Psychotherapeut, 51, 290-299. 
http://dx.doi.org/10.1007/s00278-006-0482-1

[15] Hessel, A., Geyer, M., Weidner, K. and Brähler, E. (2007) Somatic complaints among established psychological psychotherapists. Psychotherapeut, 52, 41-50. http://dx.doi.org/10.1007/s00278-006-0486-x

[16] Cierpka, M., Janssen, P.L. and Strauß, B. (2001) State of the ambulatory psychotherapeutic supply situation of adults in the Saarland. Psychotherapeut, 46, 75-81. http://dx.doi.org/10.1007/PL00006727

[17] Heisig, U. and Littek, W. (2003) The difficult path towards a profession. Psychotherapeutenjournal, 1, 7-19. http://www.psychotherapeutenjournal.de/pdfs/2003-01/02 -Beitrag1.pdf

[18] Bundesärztekammer (2003) Statistics on physicians. http://www.bundesaerztekammer.de

[19] Brähler, E. and Scheer, J.W. (1995) The Subjective Complaints List. Handbook. 2nd Edition, Huber, Bern.

[20] Fahrenberg, J., Myrtek, M., Schumacher, J. and Brähler, E. (2005) Life Satisfaction Questionnaire. Test handbook. Hogrefe, Göttingen.

[21] Alfermann, D. (2003) Occupational Stress Questionnaire. Unpublished.

[22] Rödel, A., Siegrist, J., Hessel, A. and Brähler, E. (2004) Measurement of Effort-Reward Imbalance at Work. Psychometric properties in a representative German sample. Zeitschrift für Differentielle und Diagnostische Psychologie, 25, 227-238. http://dx.doi.org/10.1024/0170-1789.25.4.227

[23] Siegrist, J., Starke, D., Chandola, T., Godin, I., Marmot, M., Niedhammer, I. and Peter, R. (2004) The measurement of effort-reward imbalance at work: European comparisons. Social Science \& Medicine, 58, 1483-1501. http://dx.doi.org/10.1016/S0277-9536(03)00351-4

[24] Bath, P.A. (2004) Differences between older men and women in the self-rated health-mortality relationship. $\mathrm{Ge}$ rontologist, 43, 387-395. http://dx.doi.org/10.1093/geront/43.3.387

[25] Benyamini, Y., Blumstein, T., Lusky, A. and Modan, B. (2003) Gender differences in the self-rated health-mortality association: Is it poor self-rated health that predicts mortality or excellent self-rated health that predicts survival? Gerontologist, 43, 396-405. http://dx.doi.org/10.1093/geront/43.3.396

[26] Heidrich, J., Liese, A., Löwel, H. and Keil, U. (2002) Self-rated health and its relation to all cause and cardiovascular mortality in Southern Germany. Annals of Epidemiology, 12, 338-345. http://dx.doi.org/10.1016/S1047-2797(01)00300-3

[27] Helmert, U. (2003) Perceived general health and mortality. Gesundheitswesen, 65, 47-54. http://dx.doi.org/10.1055/s-2003-36913
[28] Larsson, D., Hemmingsson, T., Allebeck, P. and Lundberg, I. (2002) Self-rated health and mortality among young men: What is the relation and how may it be explained? Scandinavian Journal of Public Health, 30, 259-266. http://dx.doi.org/10.1080/14034940210133997

[29] Müters, S., Lampert, T. and Maschewsky-Schneider, U. (2005) Self-rated health as predictor for mortality. Gesundheitswesen, 67, 129-136. http://dx.doi.org/10.1055/s-2005-857886

[30] Brähler, E., Schumacher, J. and Brähler, Ch. (2000) First standardisation of the short version of the Giessen-Subjective Complaints List GBB-24 in re-unified Germany. Psychotherapie Psychosomatik Medizinische Psychologie, 50, 14-21. http://dx.doi.org/10.1055/s-2000-13233

[31] Gunzelmannn, T., Schumacher, J. and Brähler, E. (1996) Subjective body complaints in the elderly: Standardization of the Giessen Subjective Complaints List (GBB-24). Z Gerontol Geriatr, 29, 110-118.

[32] Henrich, G. and Herschbach, P. (2000) Questions on life satisfaction (FLZ) — A short questionnaire for assessing subjective quality of life. European Journal of Psychological Assessment, 16, 150-159. http://dx.doi.org/10.1027//1015-5759.16.3.150

[33] Gossler, C. (2007) Health status and life satisfaction of practicing physicians. Ph.D. Thesis, University of Leipzig, Leipzig Medical School.

[34] Sieber, M., Ritz, P., Jossi, M. and Lawaczeck, K. (2008) Survey: Self-employed therapists are dissatisfied. Psychoscope, 29, 21-22. http://www.psychologie.ch/fileadmin/user_upload/dokum ente/archiv-psc/PSC_3-08.pdf

[35] Hessel, A., Brähler, E., Geyer, M. and Eichenberg, C. (2008) Aspekte der Ausbildung, der beruflichen Tätigkeit und der Lebenszufriedenheit niedergelassener Psychologischer Psychotherapeuten in Deutschland. In: Geyer, M. and Plöttner, G., Eds., Psychodynamic psychotherapy and its therapists, Psychosozial-Verlag, Gießen, 113-138.

[36] Hessel, A., Brähler, E., Geyer, M. and Eichenberg, C. (2009) About the income situation of established psychological psychotherapists. Zeitschrift für Medizinische Psychologie, 18, 180-188. http://iospress.metapress.com/content/8275372182pw503 t/fulltext.pdf

[37] Schmidbauer, W. (2004) Helpless Helpers. 13th Edition, Rowohlt, Reinbek.

[38] Fengler, J. (1997) Burnout und Psychohygiene. In: Janssen, P.L., Cierpka, M. and Buchheim, P., Eds., Psychotherapy as a profession, Vandenhoeck \& Ruprecht, Göttingen, 83-98. 